\title{
ГОСУДАРСТВЕННАЯ ПОЛИТИКА В ОБЛАСТИ ОПЛАТЫ ТРУДА В СОВРЕМЕННОЙ РОССИЙСКОЙ ЭКОНОМИКЕ: РЕГИОНАЛЬНЫЙ УРОВЕНЬ ${ }^{1}$
}

\section{THE LABOR WAGE STATE POLICY IN THE MODERN RUSSIAN ECONOMY: THE REGIONAL LEVEL}

\section{Yu. Perekarenkova}

Summary. The article considers the state policy in the field of labor wages carried out in the Russian regions. Attention is paid to the principles of wage policy, its main goals and objectives, as well as institutions involved in its implementation at the regional level. The study found that getting the opportunity to independently determine the increased minimum wage in the regions above the federal level contributed, on the one hand, to the formation of the institute of regional minimum wage agreements, and on the other hand, to the development of the regional institute of social partnership. However, the regional wage policy implemented today does not allow overcoming the existing differentiation in wages.

Keywords: regional wage policy, regional minimum wage, institute of social partnership in the regions, district coefficients.
$\mathbf{H}$ еобходимость проведения государственной политики в области оплаты труда на уровне регионов обусловлена следующими обстоятельствами.

Во-первых, получение самостоятельности в вопросах установления минимальной заработной платы в каждом субъекте Российской Федерации сверх установленного размера МРОТ на федеральном уровне позволяет сформировать подход к региональной политике заработной платы, исходя из уровня экономического развития региона, сложившегося в нем уровня жизни и т.д.

Во-вторых, возможность самостоятельного определения направления политики в области оплаты труда на уровне региона способствует развитию институтов
Перекаренкова Юлия Александровна

Н.с., Институт экономики и организации промышленного производства СО РАН (Новосибирск) perekarenkova@mail.ru

Аннотация. В статье рассмотрена государственная политика в области оплаты труда, проводимая в российских регионах. Внимание уделено рассмотрению принципов политики заработной платы, ее основных целей и задач, а также институтов, участвующих в ее реализации на региональном уровне. В ходе исследования установлено, что получение возможности самостоятельно определять повышенный размер минимальной оплаты труда в регионах сверх федерального уровня способствовало, с одной стороны, формированию института региональных соглашений о минимальной заработной плате, а с другой — развитию регионального института социального партнерства. Однако реализуемая на сегодняшний день региональная политика заработной платы не позволяет преодолеть сложившуюся дифференциацию в оплате труда.

Ключевые слова: региональная политика заработной платы, региональная минимальная заработная плата, институт социального партнерства в регионах, районные коэффициенты.

региональной минимальной заработной платы с позиции определения ее размеров, разработки механизмов индексации и т.д.

В-третьих, развитие института социального партнерства на уровне регионов предполагает выстраивание механизма установления повышенного размера минимальной оплаты труда в сравнении с федеральным уровнем. Принятие согласованного решения в установлении нижней границы оплаты труда между исполнительной властью региона, представителями профсоюзных организаций и работодателями позволит наиболее точно определить размер минимальной заработной платы, необходимый для обеспечения материальной основы воспроизводства рабочей силы в каждом конкретном субъекте РФ.

1 Статья подготовлена при финансовой поддержке Российского фонда фундаментальных исследований в рамках научного проекта № $19-010-00491$ «Исследование взаимного влияния уровня оплаты труда и воспроизводства рабочей силы в условиях макроэкономических и институциональных изменений в российской экономике в 1992-2018 гг.». 
В-четвертых, учитывая сложившуюся дифференциацию между российскими регионами по размерам начисленной средней заработной платы ${ }^{1}$, важным направлением политики заработной платы должно стать применение системы районных коэффициентов и процентных надбавок к заработной плате не только в регионах Крайнего Севера и приравненных к ним местностях. Необходимым в современных условиях является разработка системы надбавок к заработной плате в регионах с низким ее уровнем. Наличие обозначенных направлений и других моментов обуславливает необходимость ее разработки и реализации на региональном уровне.

Результаты исследований в области оплаты труда наемных работников, сложившейся в российской экономике, представлены в работах В.Е. Гимпельсона, Р.И. Капелюшникова и др. [2].

Основы формирования региональной политики заработной платы в российской экономике рассмотрены в исследованиях А.Л.Лукьяновой [3]. Исследование различий в минимальной заработной плате, сформировавшихся между российскими регионами, представлено в работе А.Ю. Ощепкова и др. [4].

В работах Н.Т. Вишневской и Е.А. Ефимовой, посвященных исследованию особенностей политики минимальной заработной платы в российской экономике в сравнении с опытом зарубежных стран, большое внимание сосредоточено на изучении ее моделей и практики их применения [5-6].

Изучение практики применения районных коэффициентов в российских регионах представлено в работах М.А. Тараканова [7].

Среди менее изученных сторон данной проблемы можно выделить исследование отличительных особенностей региональной политики заработной платы в сравнении с ее формированием на федеральном уровне, определение ее основных целей, задач, принципов и институтов, рассмотрение политики установления районных коэффициентов к заработной плате в российских регионах.

Цель статьи состоит в рассмотрении особенностей и основных направлений государственной политики в области оплаты труда, реализуемых в современной российской экономике на региональном уровне.

\footnotetext{
Например, различие в средней заработной плате между Чукотским автономным округом с развитой добывающей отраслью и Алтайским краем с ведущими отраслями специализации в промышленности и сельском хозяйстве в 2019 г. составило 3,8 раза [1].
}

Исходя из поставленной цели, в статье предполагается уделить внимание решению следующих основных задач:

1. рассмотреть особенности политики заработной платы, реализуемой в российской экономике на уровне российских регионов, определить ее цели и задачи, основные институты;

2. охарактеризовать общее содержание политики заработной платы, формируемое в принимаемых региональных соглашениях как одном из основных институтов реализации политики минимальной заработной платы на региональном уровне;

3. изучить особенности сложившейся политики формирования районных коэффициентов к оплате труда в российских регионах.

Российская модель реализации государственной политики в области оплаты труда осуществляется на двух уровнях: федеральном и региональном. На федеральном уровне разрабатываются общие принципы, формируются основные институты, регулирующие социально-трудовые отношения между работниками и работодателями, устанавливаются нормы труда и определяется нижний предел в установлении оплаты труда работников организации вне зависимости от ее формы собственности, сферы деятельности, профессии, занимаемой должности и т.д.

Определяемый в этих условиях размер минимальной заработной платы должен обеспечивать выполнение одной из основных задач всей национальной экономики - обеспечивать материальные условия для воспроизводства рабочей силы. Иными словами, устанавливаемый на федеральном уровне минимальный размер оплаты труда выступает институтом, позволяющим обеспечить реализацию данной общенациональной задачи, гарантируя пороговый уровень назначаемой заработной платы работнику в месяц на территории Российской Федерации, ниже которого воспроизводство работника становится не возможным². $^{2}$.

На региональном уровне происходит исполнение закрепленных федеральных норм, регулирующих трудовые отношения в части установления норм труда, условий его осуществления и соответствующей им оплаты за отработанное время и т.д. Учитывая, что российские регионы являются весьма неоднородными по уровню социально-экономического развития, применяемый в них единый уровень минимальной заработной платы не позволяет обеспечить равные возможности для

Рассмотрение размера минимальной заработной платы с позиции обеспечения нормального воспроизводства рабочей силы выходит за рамки настоящей статьи. 
воспроизводства занятой в них рабочей силы. Исходя из этого, основной иелью проводимой политики заработной платы на региональном уровне является регулирование экономических отношений между сторонами трудовых отношений в вопросах установления минимальной цены труда в конкретном регионе. В этом смысле предоставление регионам возможности самостоятельно устанавливать размер минимальной заработной платы выше федерального значения потенциально позволяет учесть социально-экономические, природно-климатические, демографические, геополитические и др. особенности как региона в целом, так и отдельно взятых его местностей, районов, городов и т.д.

Основной задачей, требующей решения в рамках разрабатываемой политики в области оплаты труда, является, с одной стороны, обеспечение сглаживания процессов дифференциации в заработной плате работников, как между регионами, так и внутри них, а с другой - формирование и сохранение условий для поддержания нормального уровня воспроизводства занятой рабочей силы.

Основываясь на федеральных государственных нормах и правилах регулирования трудовых отношений между работником и работодателем в вопросах труда и его оплаты, институичиональной основой государственной региональной политики в области оплаты труда выступает минимальная заработная плата. Развитие основных принципов института социального партнерства, реализуемых в рамках региональных соглашений по заработной плате, позволяет определить минимальный размер оплаты труда сверх установленного на федеральном уровне размера заработной платы отдельно для каждого региона с привлечением государства в лице органов исполнительной власти, работодателей и профсоюзов. Рассмотрим обозначенные институты более подробно.

Основным институтом, регулирующим отношения в области оплаты труда на государственном уровне, выступает минимальная заработная плата. Основываясь на исполнении статьи 133.1 Трудового кодекса Российской Федерации, в каждом регионе в рамках регионального соглашения о минимальной заработной плате может быть установлен ее повышенный размер, в сравнении с федеральным уровнем 1 . Помимо установления ее размера, в данном документе определяется период, на который утверждается размер региональной минимальной заработной платы, категории

\footnotetext{
С 1 января 2021 г., на основании применения измененной методики установления МРОТ, его величина в Российской Федерации составила 12790 рублей [8-9].
}

работников и сектора экономики, на которые распространяется действие данного соглашения, а также иные условия, обеспечивающие процесс регулирования региональной минимальной заработной платы.

\section{Введение}

данной практики регулирования механизма установления МРОТ позволяет корректировать ее размер применительно к отдельным российским регионам, учитывая сложившиеся в нем демографические, социально-экономические и др. факторы.

Одним из отрицательных моментов применения данного подхода к регулированию размера оплаты труда на уровне отдельных регионов является его распространение только на работников, занятых в организациях соответствующего субъекта Российской Федерации. При этом работники, оплата труда которых осуществляется из федерального бюджета, не относятся к сфере действия данного регионального соглашения о минимальной заработной плате. В результате минимальный уровень оплаты труда для работников бюджетного сектора устанавливается на уровне федерального значения, не учитывающего в полной мере особенности социального и экономического положения определенных регионов ${ }^{2}$. В этом, с одной стороны, прослеживается ущемление прав работников бюджетных организаций получать равную оплату на равный труд, независимо от источника финансирования (федеральный бюджет или организации регионального значения), а с другой - формируется дифференциация в оплате труда, как внутри региона между работниками разных отраслей, не учитывая уровень квалификации, сложности, трудоемкости и т.д., так и между соседними регионами ${ }^{3}$.

Следовательно, необходимо разработать механизм поддержки работников бюджетных организаций, финансируемых из федерального бюджета, например, в виде предоставления субсидий на оплату услуг ЖKX, прохождения обследования и оплаты лечения, квот на бюджетные места в образовательных учреждениях ВПО и СПО, детских дошкольных учреждениях и т.д.

Определяемая на региональном уровне минимальная заработная плата должна учитывать сложившуюся в регионе долю работников с низкой оплатой труда, различие в уровне цен, динамику ВРП. См. подробнее: [5, c. 27].

${ }^{3}$ Данный процесс, дающий регионам право устанавливать минимальный размер оплаты труда в повышенном размере (выше федерального значения), и его влияние на функционирование рынка труда рассматривался многими исследователями. Основным выводом из данных исследований является выявление негативного влияния минимальной заработной платы, выражающемся в сокращении занятости и росте безработицы. См. подробнее исследования Е.Н. Кобзарь, А. Муравьева, А. Ощепкова и др. [10-11]. 
с целью выравнивания заработной платы работников бюджетного и внебюджетного секторов экономики, выполняющих труд одинакового уровня сложности и квалификации.

Процесс регулирования региональной минимальной заработной платы осуществляется совместно с разработкой и подписанием на уровне субъектов Российской Федерации специальных трехсторонних соглашений между профсоюзной организацией, объединением работодателей и организациями исполнительной власти в конкретном регионе ${ }^{1}$, и представляет собой отдельный вид регулирования социально-трудовых отношений, реализуемых в рамках института соцчиального партнерства в конкретном субъекте РФ ${ }^{2}$.

Разрабатываемые региональные трехсторонние соглашения, касающиеся вопросов регулирования отношений в области оплаты труда, имеют свои особенности. Однако среди общих моментов, содержащихся в данных документах, можно выделить следующие:

1. минимальная заработная плата в организациях региона не может устанавливаться ниже величины, зафиксированной в региональном соглашении, федерального МРОТ и прожиточного минимума трудоспособного населения региона;

2. проведение индексации заработной платы в соответствии с ростом потребительских цен на товары и услуги в регионе;

3. установление тарифной части в общей структуре заработной платы от 50 до 70\%;

4. обеспечение своевременной выплаты заработной платы в полном объеме, соответствующем отработанному времени, установленным нормам и требованиями, предъявляемым к квалификации;

5. совершенствование практики отраслевого регулирования систем оплаты труда, направленных на сокращение дифференциации между работниками;

6. отдельные меры по развитию системы социального партнерства;

7. в регионах Крайнего Севера и приравненных к ним территориях применяется система процентной надбавки к заработной плате. Отдельные положения в отношении установления за-

\footnotetext{
Для внебюджетного сектора предусмотрена возможность отказа от поддержания данной инициативы путем направления соответствующего письменного уведомления в течение 30 дней с момента его подписания.

2 Заключаемые на территории региона трехсторонние соглашения, регулирующие общие вопросы в области социально-трудовых отношений, а также возникающие на их основе экономические отношения, выступают отдельным видом заключаемых соглашений на уровне субъекта РФ [12].
}

работной платы в этих территориях касаются молодых работников в возрасте до 30 лет.

Политика применения районных коэффицииентов способствует установлению и выплате заработной платы в повышенном размере в определенных регионах. В основном это касается работников, занятых в регионах с особыми климатическими условиями, с целью обеспечения компенсации затрат на воспроизводство рабочей силы в повышенном размере. Так, согласно ст. 315 Трудового кодекса Российской Федерации (ТК РФ) районные коэффициенты и процентные надбавки, увеличивающие размер оплаты труда, применяются в районах Крайнего Севера и приравненных к ним территориях. Размеры районных коэффициентов и порядок их установления утверждается Правительством Российской Федерации.

Однако размер данных коэффициентов может быть пересмотрен на уровне субъектов и органов местного самоуправления субъектов Российской Федерации за счет средств бюджетов соответствующих регионов и территориальных образований в сторону их увеличения (ст. 316 ТК РФ). Процентная надбавка к заработной плате за отработанный стаж выплачивается работникам, занятым в организациях Крайнего Севера и приравненным к ним местностям (ст. 317 ТК РФ).

За счет этого увеличения средняя заработная плата в данных субъектах Российской Федерации сохраняется на более высоком уровне. Однако, необходимо учитывать, во-первых, что увеличенный размер оплаты труда и соответственно повышенный размер районных коэффициентов и надбавок к ней в данных субъектах в основном распространяется на отдельные районы, местности, города и т.д., тем самым не охватывая население всего региона и всех категорий работников, что является предпосылкой для формирования дифференциации в оплате труда внутри региона.

Во-вторых, существующая политика применения районных коэффициентов к оплате труда распространяется также на территории, не относящиеся к районам Крайнего Севера и приравненные к ним местности. Тем не менее, несмотря на увеличение уровня оплаты труда за счет использования данных коэффициентов, во многих из них не решается проблема низкой оплаты труда. Например, в Республиках Дагестан и Калмыкия, Кабардино-Балкарской Республике, Алтайском крае, где, несмотря на применяемые районные коэффициенты к заработной плате, ее средняя величина составляла в 2019 г. от 26 до 28 тыс. рублей в месяц [1].

В-третьих, применяемая в половине субъектов Российской Федерации политика формирования оплаты 
труда без использования районных коэффициентов не позволяет увеличить на их величину низкий уровень оплаты труда. Однако, несмотря на то, что данные регионы не относятся к местностям с особыми климатическими условиями, в силу чего в них отсутствуют основания для разработки и применения районных коэффициентов, не позволяет говорить о наличии в них полноценных условий для воспроизводства наемной рабочей силы (например, Брянская область, Республика Северная Осетия).

Исходя из рассмотренных направлений политики заработной платы, реализуемой на уровне российских регионов, можно сделать вывод о том, что в современных условиях политика установления минимальной заработной платы на уровне субъектов Российской Федерации позволяет им самостоятельно определять повышенный размер минимальной заработной платы, исходя из сложившихся в них социально-экономиче- ских условий. Однако, учитывая низкий уровень минимальной заработной платы, ее увеличение в отдельных регионах не способствует решению этой проблемы в части обеспечения воспроизводственной функции оплаты труда в целом в российской экономике.

Не решает эту проблему для большей части российских регионов применяемая политика установления районных коэффициентов. Их повышенный размер установлен в районах Крайнего Севера и приравненных к ним местностях, где и так, исходя из отраслевой специализации и действующей в целом разработанной системы надбавок к заработной плате, оплата труда устанавливается в повышенном размере в сравнении с другими российскими регионами. Следовательно, необходима разработка системы надбавок к заработной плате в регионах с низкой оплатой труда, направленной на обеспечение условий воспроизводства занятой в них рабочей силы.

\section{ЛИТЕРАТУРА}

1. Социально-экономические показатели по субъектам Российской Федерации: приложение к сборнику «Регионы России. Социально-экономические показатели» [Электронный ресурс].— URL: https://rosstat.gov.ru/storage/mediabank/81XNUHM5/pri-region2020.rar (дата 0бращения: 12.08.2021).

2. Гимпельсон В.Е., Капелюшников Р.И. Заработная плата в России. Эволюция и дифференциация / Под ред. В.Е. Гимпельсона, Р.И. Капелюшникова. 2-е изд.- М.: ВШЭ, 2008. - 575 с.

3. Лукьянова А.Л. Практика установления региональных минимальных заработных плат в субъектах Российской Федерации (2007-2015) // Вопросы государственного и муниципального управления. — 2016. — № 1. - С. 81-102.

4. Ощепков А.Ю. Межрегиональные различия в оплате труда в России: роль долгосрочных структурных факторов: препринт WP3/2019/08. - М.: Изд. дом Высшей школы экономики, 2019. - 40 с.

5. Вишневская Н.Т. Регионализация минимальных заработных плат // Вопросы государственного и муниципального управления.— 2016. - № 4. C. 27-44.

6. Ефимова Е.А. Установление минимальной заработной платы: зарубежный опыт и российская практика // Мировая экономика и международные отношения. - 2011. — № 2.- С. 24-35.

7. Тараканов М.А. Районные коэффициенты — реальная реформа без северного изоляционизма // Дайджест-Финансы.— 2007.— № 3 (147).— C. $31-38$.

8. 0 минимальном размере оплаты труда: федеральный закон от 19.06.2000 г. № 82-Ф3: принят Гос. Думой 2 июня 2000 года; ред. 0 т 29.12 .2020 г. Доступ из справ. -правовой системы «Консультант-Плюс».

9. О внесении изменений в отдельные законодательные акты Российской Федерации: федеральный закон от 29 декабря 2020 г. № 473-Ф3: принят Гос. Думой 16 декабря 2020 г. // Российская газета.— № 1.- 11.01.2021.

10. Кобзарь Е.Н. Минимальная заработная плата и региональные рынки труда в России: препринт WP15/2009/06. — М.: Изд. дом ГУ ВШЭ, 2009. — 56 с.

11. Muravyev A., Oshchepkov A. Minimum wages and labor market outcomes: Evidence from the emerging economy of Russia. - Basic Research Program at the National Research University Higher School of Economics (HSE) // Working Papers. — Series: Economics. — WP BRP 29/EC/2013. — 2013. — 33 p.

12. Сафонов В.А. Региональное соглашение о минимальной заработной плате в субъекте Российской Федерации: теоретические проблемы // Труд и социальные отношения. — 2019. — Т. 30. — № 1.— C. 146-154. D0I 10.20410/2073-7815-2019-30-1-146-154.

(c) Перекаренкова Юлия Александровна ( perekarenkova@mail.ru).

Журнал «Современная наука: актуальные проблемы теории и практики» 